9. Su D, Esqueda OA, Li L, et al. Income inequality and obesity prevalence among OECD countries. J Biosoc Sci 2012;44:417-32. http://dx.doi.org/10.1017/S002193201100071X

Correspondence: Dr. Darren Beiko, Department of Urology, Queen's University, Kingston General Hospital, 76 Stuart St., Kingston, ON K7L 2V7; fax: 613-545-1970; beiko@queensu.ca

\section{Continuing medical education: The perspective of quality improvement}

\author{
Kieran Walsh, FRCPI \\ BMJ Learning, BMJ Publishing Group, London, UK
}

Cite as: Can Urol Assoc J 2014;8(1-2):23. http://dx.doi.org/10.5489/cuaj.1767

Published online February 10, 2014.

A hmed and colleagues are to be congratulated for their scholarly review of the effectiveness of continuing medical education (CME) for the purposes of specialist recertification. ${ }^{1}$ They are correct to point out the dangers of healthcare professionals viewing CME as a method of accumulating credits for its own sake - rather than as a means of improving their practice. This is likely to be particularly at issue in the case of specialist CME where an individual tertiary care specialist may gather the requisite number of credits, but still not do much CME that relates directly to their clinical practice and thus that will improve their clinical practice. In any case, education is not like a drug - it is difficult to definitively prove its "effectiveness" by means of traditional quantitative research trials. It is likely that another perspective is called for.

That perspective may best come from the paradigm of improvement science rather than that of education. It may be better for specialists to measure key outcomes of their practice at baseline, institute clinical quality improvement measures and continually re-measure and measure at the end of a fixed period. At the end they might evaluate the improvement project and see what they have learned. Improvement may thus result in learning, rather than learning resulting in improvement. The key advantage of this approach is that it would result in a project tailored to the individual clinician's need - regardless of their degree of specialization.

Finally the authors are right to draw their review to a close with research questions for the future. To their list of questions, I would add 2 more: (1) should CME be a teambased activity rather than an individual activity?; and (2) what forms of CME offer best value for the sums spent on them? CME has become a multimillion dollar industry. If we are to continue to invest, surely we should have better data on cost-effectiveness, cost benefits or cost utility?

Competing interests: Mr. Walsh is Editor of BMJ Learning at the British Medical Association.

\section{References}

1. Ahmed K, Wang TT, Ashrafian H, Layer GT, Darzi A, Athanasiou T. The effectiveness of continuing medical education for specialist recertification. Can Urol Assoc J. 2013 Jul;7(7-8):266-272. http://dx.doi. org/10.5489/cuai.378

2. Walsh $\mathrm{K}$, Levin $\mathrm{H}$, Jaye P, Gazzard J. Cost analyses approaches in medical education: there are no simple solutions. Med Educ. 2013 0ct;47(10):962-8. http://dx.doi.org/10.1111/medu.12214

Correspondence: Dr. Kieran Walsh, BMJ Learning, BMA House, Tavistock Square, London WCIH 9JR; kmwalsh@bmigroup.com 